\title{
Can Multisensorial Media Improve Learner Experience?
}

\author{
Longhao Zou \\ Dublin City University \\ School of Electronic Engineering \\ Dublin, Ireland \\ longhao.zou@dcu.ie \\ Eva Ibarrola \\ University of the Basque Country \\ NQAS Research Group \\ Bilbao, Spain \\ eva.ibarrola@ehu.eus
}

\author{
Irinal Tal \\ Dublin City University \\ School of Electronic Engineering \\ Dublin, Ireland \\ irina.tal2@mail.dcu.ie \\ Gheorghita Ghinea \\ Brunel University London \\ Department of Computer Science \\ London, UK \\ george.ghinea@brunel.ac.uk
}

\author{
Alexandra Covaci \\ Brunel University London \\ Department of Computer Science \\ London, UK \\ alexandra.covaci@brunel.ac.uk \\ Gabriel-Miro Muntean \\ Dublin City University \\ School of Electronic Engineering \\ Dublin, Ireland \\ gabriel.muntean@dcu.ie
}

\begin{abstract}
In recent years, the emerging immersive technologies (e.g. Virtual/Augmented Reality, multisensorial media) bring brand-new multi-dimensional effects such as 3D vision, immersion, vibration, smell, airflow, etc. to gaming, video entertainment and other aspects of human life. This paper reports results from an European Horizon 2020 research project on the impact of multisensoral media (mulsemedia) on educational learner experience. A mulsemediaenhanced test-bed was developed to perform delivery of video content enhanced with haptic, olfaction and airflow effects. The results of the quality rating and questionnaires show significant improvements in terms of mulsemedia-enhanced teaching.
\end{abstract}

\section{CCS CONCEPTS}

-General and reference $\rightarrow$ Experimentation; -Information systems $\rightarrow$ Multimedia information systems; $\cdot$ Human-centered computing $\rightarrow$ Interaction devices; Interaction techniques; Interaction paradigms; •Applied computing $\rightarrow$ E-learning;

\section{KEYWORDS}

E-learning, Multisensory, User Experience

\section{ACM Reference format:}

Longhao Zou, Irinal Tal, Alexandra Covaci, Eva Ibarrola, Gheorghita Ghinea, and Gabriel-Miro Muntean. 2017. Can Multisensorial Media Improve Learner Experience?. In Proceedings of MMSys'17, Taipei, Taiwan, fune 20-23, 2017, 6 pages.

DOI: http://dx.doi.org/10.1145/3083187.3084014

\section{INTRODUCTION}

The rapid growth and development of information and communication technologies have determined fast evolution of technology enhanced learning (TEL), evolution which is likely to continue.

Permission to make digital or hard copies of all or part of this work for personal or classroom use is granted without fee provided that copies are not made or distributed for profit or commercial advantage and that copies bear this notice and the full citation on the first page. Copyrights for components of this work owned by others than ACM must be honored. Abstracting with credit is permitted. To copy otherwise, or republish, to post on servers or to redistribute to lists, requires prior specific permission and/or a fee. Request permissions from permissions@acm.org.

MMSys'17, Taipei, Taiwan

(c) 2017 ACM. 978-1-4503-5002-0/17/06 ..\$15.00

DOI: http://dx.doi.org/10.1145/3083187.3084014
Many reports and surveys have shown that TEL in general and mobile learning in particular are not showing signs of regression after the fast growth registered in the last decade [6]. On the contrary, an increasing number of individuals, corporations, and institutions are showing interest in TEL, mostly due to its effectiveness and market potential: for instance, the learning management systems (LMS) market was worth $\$ 2.55$ billion in 2013 and it is expected to be worth over $\$ 7$ billion in $2018^{1}$. Although many advancements have been noted in the context of TEL, there are many avenues for additional improvement.

The study in this paper is funded by a European Horizon 2020 NEWTON project that brings together academia and industry partners from several different European countries. NEWTON project aims to provide a pan-European learning platform that facilitates the delivery of STEM (Science, Technology, Engineering and Mathematics) subjects to learners from a variety of backgrounds: secondary and vocational schools, third level education, people with disabilities. This pan-European platform will integrate a set of distributed labs: remote labs enhanced with fabrication technologies (i.e. Fab Labs ${ }^{2}$ ) and state-of-the-art remote teaching labs - virtual labs -, created as result of the project. The aim of this platform is to go beyond the classic functionality of LMS by connecting the students with various Fab Labs and virtual labs to allow access to an increased volume of learning content and also to improve their learning experience. Additionally the platform aims to enhance the classic LMS functionality with innovative TEL solutions. The purpose of these solutions is to both increase user/learner quality of experience (QoE) and their learning outcome. The innovative TEL methods that are developed in the context of this project relate to:

- Learner model-based personalisation

- Gamification

- Multimedia and multi-sensorial (mulsemedia) content delivery. Mulsemedia is considered a new type of multimedia that unlike classic multimedia that usually involves two senses (audio/video), involves three or more human senses (olfactory, haptic, etc.).

\footnotetext{
${ }^{1} \mathrm{https} / /$ elearningindustry.com/elearning-statistics-and-facts-for-2015 ${ }^{2}$ https://www.fablabs.io/
} 
- Adaptation of content delivery to learner operational environment: variation of network conditions, user device characteristics and user profile.

The focus in this paper is on the mulsemedia component, and NEWTON project aims to provide the learners with increased mulsemedia experience in order to enhance their overall learning experience. Additionally the multiple-sensorial content will be delivered in an adaptive manner depending on the learner operational characteristics and learner profile. To the best of authors knowledge mulsemedia has not been employed in TEL before. The idea of using mulsemedia as a TEL method is based on research studies in neuroscience that suggest as a best practice in learning the engagement of multiple senses (i.e. as many senses as possible). The neuroscience researchers argue that learning can be deeper, richer, more memorable (i.e. increased learner and learning experience) and more effective an experience when multiple senses are involved [3]. In [10], the importance of the multisensorial exposure in learning is also highlighted. The authors emphasize on the fact that people have a multisensory brain that has evolved to develop, learn and operate in a multisensory environment. Therefore, a multisensory-based learning setting is natural for the human brain, will enhance the brain functions and consequently is more suitable for the learning process as compared to any uni-sensorial learning setting.

This paper makes the first steps in the analysis of whether mulsemedia can enhance learner QoE and how open learners are to use mulsemedia in their learning process. The structure of the paper is as follows: Section II presents a review of different TEL methodologies, stating their impact in learner QoE, section III presents the mulsemedia-enhanced teaching experiments performed in the context of our analysis on mulsemedia impact on learner QoE. Section IV discusses the results of the tests performed, while last section draws the conclusions.

\section{RELATED WORKS}

With the growing interest on eLearning in general and mobile learning in particular, very much effort has been invested in the TEL area. Various technologies have been put to use to enhance learning such as Augmented Reality (AR)/Virtual Reality (VR) ${ }^{3}$, game-based learning and gamification [2] [8] and adaptive techniques applied to the content in order to suit learner's context. Some solutions started to integrate more than just one such technology as it is the case of the work presented in [2] where game-based learning is combined with an adaptive solution that takes into account the energy factor, as the proposed solution is dedicated to the particular case of mobile learning. One of the main purposes of these TEL methods is to improve learning experience and learner QoE.

In [9], it is shown how adapting the content depending on the network conditions can lead to the improvement in learner QoE, while [5] underlines that there is a clear need for adapting the learning multimedia content to the learner context. This learner context can be defined by device characteristics (e.g. screen resolution, CPU performance, battery), network conditions and user profile (e.g. age, different preferences). Recent works have focused on a device-oriented content adaptation ([14], [15]) The work presented

\footnotetext{
${ }^{3}$ https://techcrunch.com/2016/01/23/when-virtual-reality-meets-education/
}

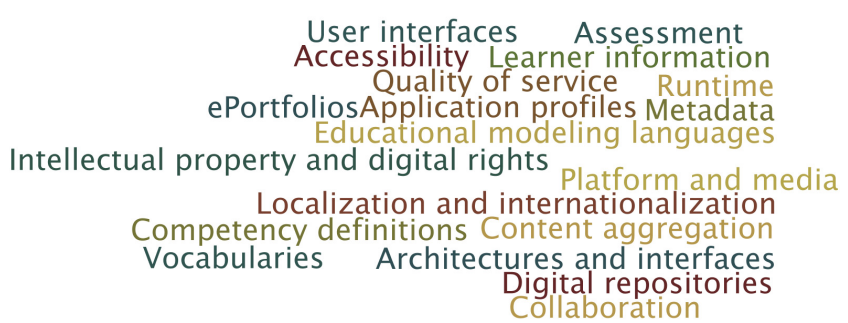

Figure 1: Items addressed by TEL-related standards in ITU[1]

in [14] shows for instance how a content adaptation driven by device characteristics can lead to an optimal trade-off between QoE and energy savings, highly required in mobile learning. Other very recent studies [7] are focusing on the aspect of balancing between content adaptation and learner QoE with the aim of maximizing the later.

Other works in the literature aim to build appropriate models for predicting the learner QoE when TEL is employed. Such work is for instance the one presented in [12] that introduces a fuzzy logic-based predictive system for estimating learner QoE levels. The system considers both subjective (e.g. learning style) and objective factors (e.g. network conditions).

Moreover, standardization efforts have been put in this area. ITU (International Telecommunication Union) has ongoing standardization activities in the area of TEL that relate to the topics presented in Fig.1. In this context, worth mentioning is Recommendation ITU-T F.742 ${ }^{4}$ which describes application scenarios of distance learning and deduces general requirements to be met by distance learning services. Other standardization bodies are performing similar activities: e.g. ISO/IEC FTC1 Subcommittee 36 Information technology for learning, education and training ${ }^{5}$ or The IEEE Learning Technology Standards Committee (LTSC) ${ }^{6}$. LTSC committee is developing a standard model for defining AR-based learning activities (i.e. Augmented Reality Learning Experience Model). A very recent work [11] introduces a novel standardization proposal in the area of TEL. This consists of a framework aiming to evaluate learner QoE when subject to TEL.

\section{MULSEMEDIA-ENHANCED TEACHING EXPERIMENTS}

\subsection{Mulsemedia-Enhanced Test-bed}

In order to study the effect of mulsemedia in reality, a mulsemediaenhanced test-bed was developed for the mulsemedia-enhanced teaching experiments. As shown in Fig. 2, the test-bed consists of two subsystems: the Mulsemedia Player and the Mulsemedia Device Controller:

\footnotetext{
${ }^{4}$ ITU-T. F.742: Service description and requirements for distance learning services, ed. Geneve, Switzerland, 2005

${ }^{5}$ ISO/IEC. (1999). ISO/IEC JTC1 Subcommittee 36: Information technology for learning, education and training.

${ }^{6}$ IEEE. (2016). The IEEE Learning Technology Standards Committee. Available: https://ieee-sa.imeetcentral.com/ltsc/
} 


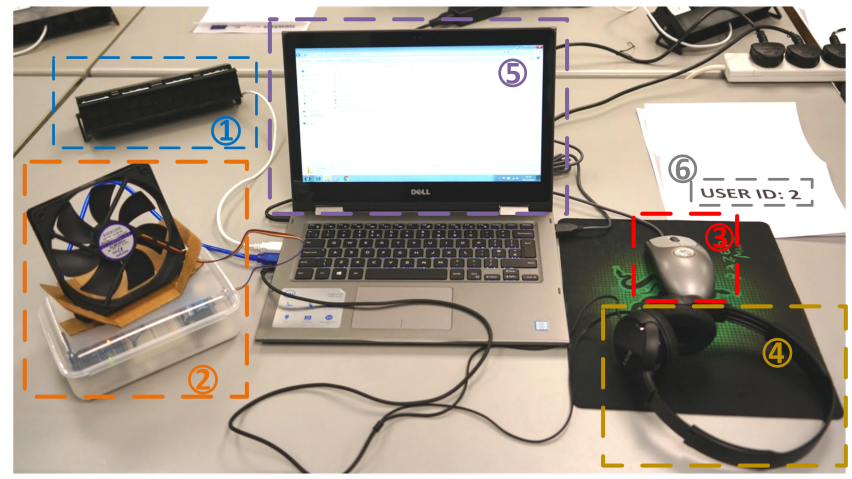

Figure 2: Mulsemedia-enhanced Teaching Testbed

Mulsemedia Player was developed based on the VideoLan player (VLC Nightly Build 3.0 and higher) ${ }^{7}$, which performs 2D/3D video streaming, decoding and playback. In the testbed, the mulsemedia player decodes the testing videos with the mulsemediaenhanced time-stamped scripts, and then synchronizes the timestamped information with the Mulsemedia Device Controller. The time-stamped script involves the type, duration (i.e. time of start and time of end), intensity and speed of the specific mulsemedia effect.

Mulsemedia Device Controller which was written in $\mathrm{C}++$ and $\mathrm{C} \#$ controls the multisensorial devices by retrieving the timestamped scripts of the mulsemedia-enhanced videos. In these mulsemedia-enhanced teaching experiments, the Mulsemedia Device Controller works with a haptic device, airflow generator, olfaction diffuser and headphone (i.g. see the numbered equipment in Fig. 2):

(1) Olfaction Diffuser: It is made by Exhalia ${ }^{8}$ and includes four aroma cartridges which are diffused by small rear controllable fans. The Mulsemedia Controller can adjust the intensity and duration of functionality for each small fan.

(2) Airflow Generator: It is developed based on a computer case fan $(12 \mathrm{~V})$ and controlled by the Arduino board with different intensities, fan speeds and durations.

(3) Haptic Device: It is a modified version of the Logitech iFeel Mouse ${ }^{9}$, and its vibrating type, intensity and duration are programmable by the Mulsemedia Controller using C++ code.

(4) Headphone: The Sony ZX310 on-ear headphone (see item No.4 in Fig. 2) ${ }^{10}$ is used to obtain high quality audio effects without noise during the testing.

\subsection{Mulsemedia-enhanced Video Encoding}

In the experiments, 7 (seven) short video clips are selected from each of the movies Furassic Park and Back to the Future. The video formats and the decoded time-stamped effect information of the selected video clips are shown in Table 1 . The selected video clips

\footnotetext{
${ }^{7}$ videoLan http://www.videolan.org/vlc/index.html

${ }^{8} \mathrm{http}: / /$ www.exhalia.com/fr/

${ }^{9} \mathrm{https} / /$ www.amazon.com/exec/obidos/asin/b00005asfk/ifeelpixel-20

${ }^{10} \mathrm{https} / / /$ www.sony.ie/electronics/headband-headphones/mdr-zx310-zx310ap
}

use the 2500kbps H.264/MPEG4 baseline profile and 30fps@720p, and four different mulsemedia effect scenarios are associated with these 7 video clips, as follows:

- Haptic-Only Scenario (i.e. 2d_h_h_bf): this scenario performs the haptic effect only associated with running persons and gunfight.

- Olfaction-Only Scenario (i.e. 2d_o_jp): this scenario is associated with an outstanding aroma coming from food.

- Airflow-Only Scenario (i.e. 2d_w_bf): this scenario includes wind effect only.

- Mixture-Effect Scenarios (i.e. the rest of the clips): haptic, airflow and olfaction effects are mixed in these complex scenarios which include high-mobility vehicles and gunfights.

\subsection{Mulsemedia-enhanced Testing Procedure}

In the mulsemedia-enhanced teaching experiments, an unique user ID is allocated to each anonymous participant (see item No.6 in Fig. 2 ), and the testing procedure consists of two parts:

- Video Testing and Rating: In this part, the procedure is divided into two sections, as shown in Fig.3: Mulsemediadisabled Testing Section and Mulsemedia-enabled Testing Section. Following the instruction in Fig. 3, the participant inputs the user ID, and watches the clips while feeling the effects performed by the mulsemedia equipment. Finally the learner takes a break to answer the user perception related questions.

- Overall Questionnaire: After the video testing and experience quality rating, the participant is requested to answer a few questions which are related to the overall perception quality and learning outcome impacts for the whole mulsemedia-enhanced test-bed.

\subsection{Mulsemedia-enhanced Testing Venues and Participants}

The first studies based on mulsemedia enhanced lessons were carried out in two universities from two different European countries with different languages and cultural backgrounds, namely University of the Basque Country (UPV/EHU), Spain and Dublin City University (DCU), Ireland. The studies targeted master students attending the "Performance of Data Networks" in DCU ) and "Performance on Telecommunications Networks" course in $\boldsymbol{U P V} / \boldsymbol{E H U}$, respectively. The same lecture was delivered to both groups of students, with the only difference being that in $\boldsymbol{U P V} / \mathbf{E H U}$ the lesson was delivered in Spanish, while in $\boldsymbol{D C U}$ it was delivered in English. A part of the lesson was delivered using traditional methodologies (i.e. power point) and the other part was delivered using mulsemedia support, respectively. In final, all the results of the experiments were collected, processed and discussed. This discussion is detailed in the next section.

\section{RESULTS AND ANALYSIS}

The main goals of the study were to measure the following aspects:

- The influence of mulsemedia on increasing learner QoE

- The level of acceptance of mulsemedia as a TEL technique. 
Table 1: Testing Video Descriptions

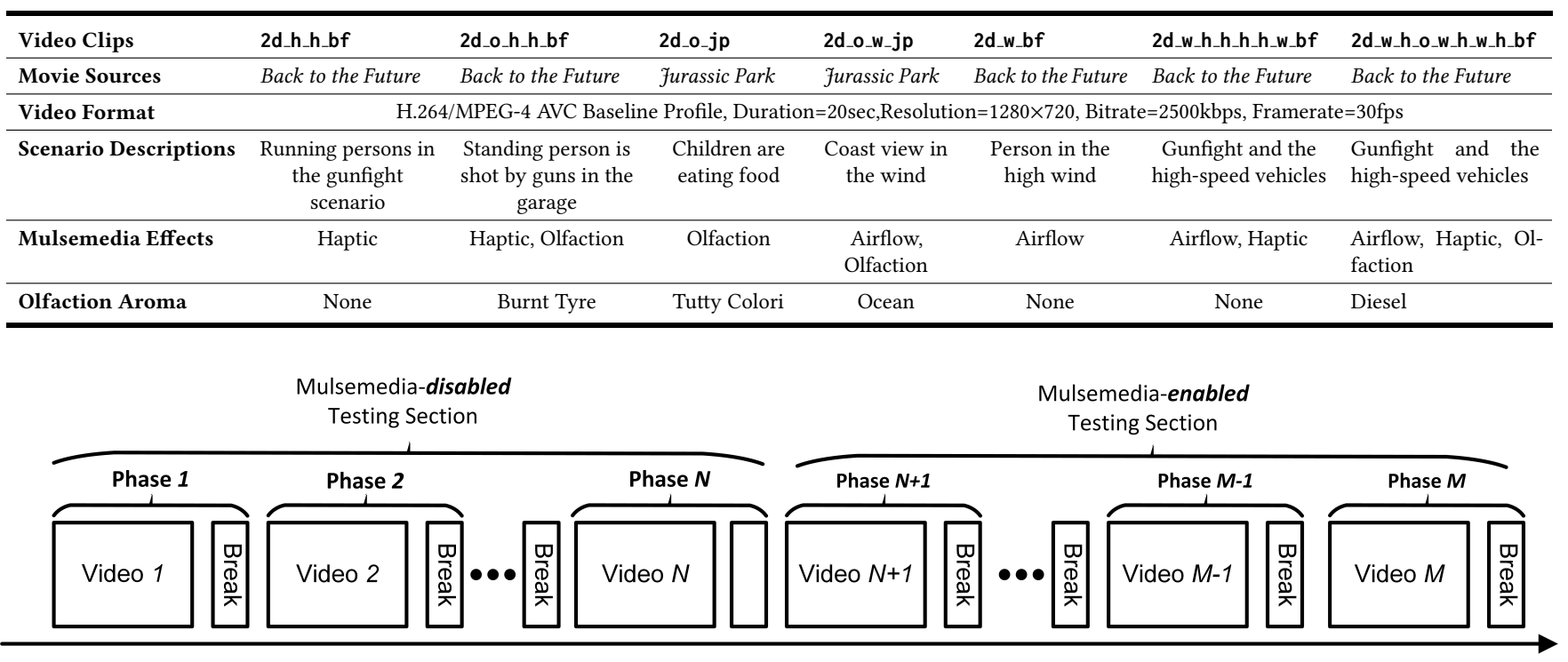

Figure 3: Video Testing and Rating Procedure

\subsection{Video User Perception Analysis: Mulsemedia-enabled vs. Mulsemedia-disabled}

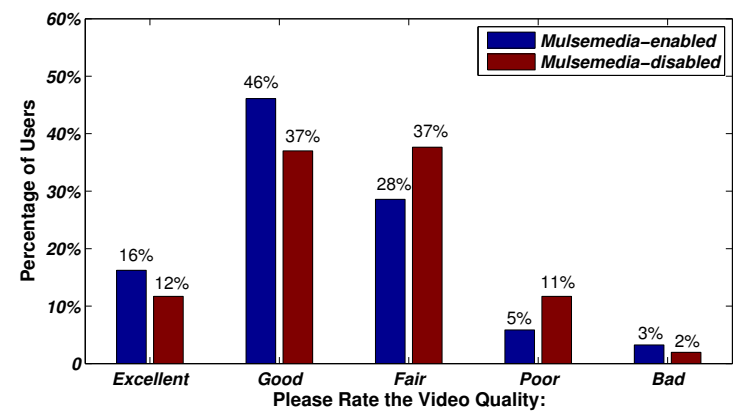

Figure 4: Video Quality Rating

Since many existing works have shown that the video quality affects the user perceived experience in the teleconferencing and the distance education $[4,13]$, the overall video user perception (QoE) results for 42 students from two difference universities (i.e. DCU and UPV/EHU) are discussed in this subsection.

In Fig.4, 14\% more participants considered the mulsemedia-enabled video as "Good" and "Excellent", in comparison with those exposed to multimedia content only. $9 \%$ and $6 \%$ fewer participants graded their experience in terms of "Fair" and "Poor" on the same five point rating scale and finally, around $1 \%$ more learners did not like mulsemedia-enabled video clips in comparison with the mulsemedia-enhanced approach.

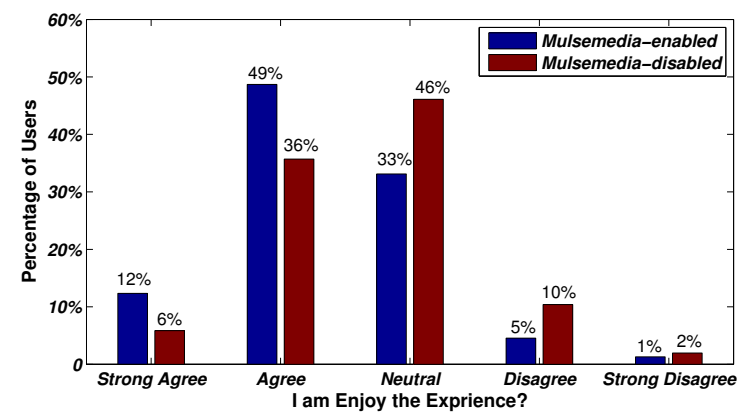

Figure 5: User Enjoyment Experience

Similarly, as shown in Fig.5, 19\% more participants found enjoyable or very enjoyable their experience during the mulsemediaenabled video tests, and consequently the proportions of "Neutral", "Disagree" and "Strong Disagree" learners have decreased accordingly.

\subsection{Educational Learner Experience Analysis: $D C U$ vs. UPV/EHU}

In order to study the educational learner experience in the overall mulsemedia-enhanced tests, a summary of the questionnaire results are presented below.

In $\boldsymbol{D C U}$ tests, all the enrolled master students to the aforementioned module participated. In total, there were 20 participants. There was a similar situation in $\boldsymbol{U P V} / \mathbf{E H U}$, where a total of 22 students participated in the pilot study. The answers of the participants to the questions presented to them in the questionnaire are briefly summarized below. Note that the following five point 


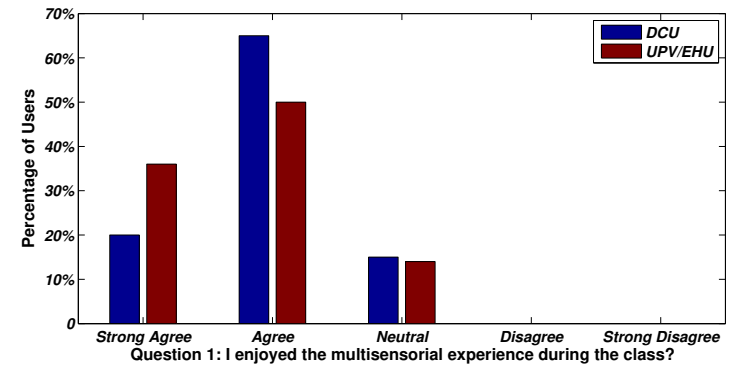

Figure 6: Question 1: I enjoyed the multisensorial experience during the class.

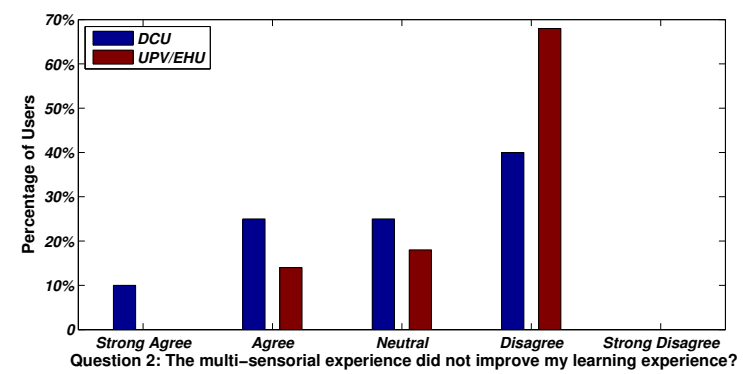

Figure 7: Question 2: The multi-sensorial experience did not improve my learning experience

scale was used in these questions: "strongly disagree", "disagree", "neutral", "agree" and "strongly agree".

Question 1: I enjoyed the multisensorial experience during the class; In case of $\boldsymbol{D C U}$ students, $85 \%$ agreed and strongly agreed on this, and the rest were neutral, while in case of $\boldsymbol{U P V / E H U}$ students $86.4 \%$ agreed and strongly agreed on this, and the rest were neutral, as shown in Fig. 6. There was no disagreement or strongly disagreement on this matter amongst the students from both the two universities, asshown in Fig. 6.

Question 2: The multi-sensorial experience did not improve my learning experience; In case of $\boldsymbol{D C U}$ students, 35\% agreed and strongly agreed, $25 \%$ were neutral and the rest of $40 \%$ disagreed, as shown in Fig. 7. In case of $\boldsymbol{U P V} / \boldsymbol{E H U}$ students, $13.6 \%$ agreed, $18.2 \%$ were neutral and the rest of $68.2 \%$ disagreed, as shown in Fig. 7.

Question 3: The multi-sensorial effects were disturbing for me during the class; In case of $\boldsymbol{D C U}$ students, $25 \%$ agreed on this aspect, $25 \%$ were neutral and the rest of $50 \%$ disagreed and strongly disagreed, as shown in Fig. 8. The students from $\boldsymbol{U P V} / \boldsymbol{E H U}$ were not disturbed at all by the multisensorial effects as $36.4 \%$ strongly disagreed on this matter, $45.4 \%$ disagreed, and the rest of $18.2 \%$ were neutral, as shown in Fig. 8.

Question 4: I would like to have more classes/labs/courses that include multi-sensorial experience; In case of $\boldsymbol{D C U}$ students, $75 \%$ agreed and strongly agreed, while $5 \%$ were neutral and $20 \%$ disagreed, as shown in Fig. 9. In case of $\boldsymbol{U P V / E H U}$ students, 77.3\% agreed and strongly agreed, while $18.2 \%$ were neutral and $4.5 \%$ disagreed, as shown in Fig. 9.

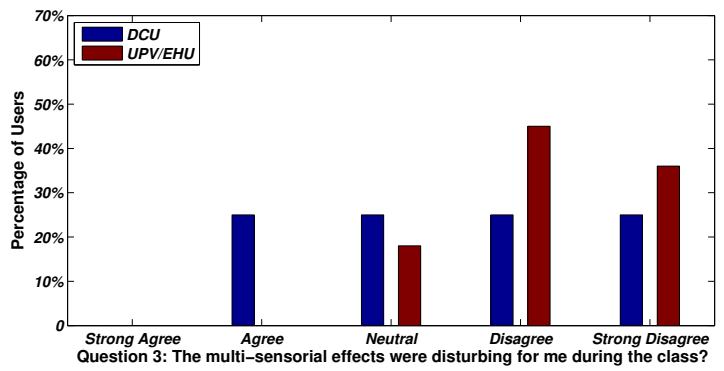

Figure 8: Question 3: The multi-sensorial effects were disturbing for me during the class.

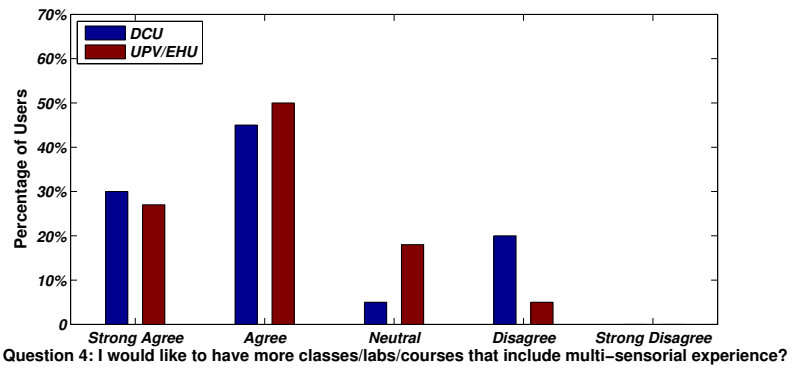

Figure 9: Question 4: I would like to have more classes/labs/courses that include multi-sensorial experience

The results show that the vast majority of the students have enjoyed the mulsemedia experience during the class. Note none of the students gave a negative feedback regarding this aspect (see Question 1), although some students from $\boldsymbol{D C U}$ declared they were disturbed by the multi-sensorial effects (i.e. Question 3). In addition, the majority of the students said that mulsemedia improved their learning experience (Question 2) in general. Taking into consideration these answers and all the above-mentioned, aspects we are entitled to conclude that mulsemedia as a TEL technology can lead to an improvement in learner QoE.

The above considerations, but especially the answers to Question 4 show that the students are very open to mulsemedia as a TEL technology, the vast majority of them being eager to participate in more mulsemedia enhanced teaching sessions.

\section{CONCLUSION}

This paper aimed to perform the first steps in analyzing the impact of mulsemedia as a TEL methodology in general and impact of mulsemedia on learner QoE in particular. A mulsemedia-enhanced teaching test-bed was developed to perform different multisensorial effects (i.e. haptic, olfaction and airflow) while the audience is watching video clips. The mulsemedia-enhanced teaching experiments were carried out in two different European countries with different languages and cultures, $\boldsymbol{D C} \boldsymbol{U}$ and $\boldsymbol{U P V} / \boldsymbol{E H U}$, Ireland and Spain, respectively.

Master students who subscribed to similar courses were placed in the same teaching context and were targeted with identical content 
in this study. The results of video perception rating and user satisfaction questionnaires were collected and processed. The results demonstrate that mulsemedia-enabled video has better enjoyment and majority of the students are very open to mulsemedia as a TEL technology, as it increases their learner experience. In the future, more learning courses and pilots will be considered and evaluated for more participants across different European countries in the context of this EU funded project.

\section{REFERENCES}

[1] Martin Adolph. 2012. Standards for technology-enabled learning. ITU-T Technology Watch Report, ITU (2012).

[2] Ioana Ghergulescu, Arghir-Nicolae Moldovan, and Cristina Hava Muntean. 2014. Energy-aware Adaptive Multimedia for Game-based E-learning. In Broadband Multimedia Systems and Broadcasting (BMSB), 2014 IEEE International Symposium on. IEEE, 1-6.

[3] Ronni Hendel-Giller, Cindy Hollenbach, David Marshall, Kathy Oughton, Tamra Pickthorn, Mark Schilling, and Giulietta Versiglia. 2011. The Neuroscience of Learning: A New Paradigm for Corporate Education.

[4] Jonathan K Kies, Robert C Williges, and Mary Beth Rosson. 1997. Evaluating desktop video conferencing for distance learning. Computers \& Education 28, 2 (1997), 79-91.

[5] Arghir-Nicolae Moldovan and Cristina Hava Muntean. 2011. Towards personalised and adaptive multimedia in m-learning systems. (2011).

[6] Arghir-Nicolae Moldovan, Stephan Weibelzahl, and Cristina Hava Muntean. 2014. Energy-aware mobile learning: Opportunities and challenges. IEEE Communications Surveys \& Tutorials 16, 1 (2014), 234-265.

[7] Andreea Molnar. 2016. Content type and perceived multimedia quality in mobile learning. Multimedia Tools and Applications (2016), 1-15.

[8] Andreea Molnar and Patty Kostkova. 2013. On effective integration of educational content in serious games: Text vs. game mechanics. In Advanced Learning Technologies (ICALT), 2013 IEEE 13th International Conference on. IEEE, 299-303.

[9] Cristina Hava Muntean. 2008. Improving learner quality of experience by content adaptation based on network conditions. Computers in Human Behavior 24, 4 (2008), 1452-1472.

[10] Ladan Shams and Aaron R Seitz. 2008. Benefits of multisensory learning. Trends in cognitive sciences 12,11 (2008), 411-417.

[11] Irina Tal, Eva Ibarrola, and Gabriel-Miro Muntean. 2016. Quality and Standardization in Technology-Enhanced Learning. In ITU Kaleidoscope: ICTs for a Sustainable World (ITU WT), 2016. IEEE, 1-8.

[12] Tatjana Vasileva-Stojanovska, Marina Vasileva, Toni Malinovski, and Vladimir Trajkovik. 2015. An ANFIS model of quality of experience prediction in education Applied Soft Computing 34 (2015), 129-138.

[13] Anna Watson and Martina Angela Sasse. 1996. Evaluating audio and video quality in low-cost multimedia conferencing systems. Interacting with Computer 8, 3 (1996), 255-275.

[14] Longhao Zou, Ramona Trestian, and Gabriel-Miro Muntean. 2014. eDOAS Energy-aware device-oriented adaptive multimedia scheme for Wi-Fi offload. In Wireless Communications and Networking Conference (WCNC), 2014 IEEE. IEEE, 2916-2921.

[15] Longhao Zou, Ramona Trestian, and Gabriel-Miro Muntean. 2015. E 2 DOAS: user experience meets energy saving for multi-device adaptive video delivery. In Computer Communications Workshops (INFOCOM WKSHPS), 2015 IEEE Conference on. IEEE, 444-449. 